with $7 \%$ in hospital and $26 \%$ psychotic of the " phenothiazinetreated" group. The methods of selection, the environment, and the general treatment setting were the same for both groups. Very little if any detailed psychotherapy was found necessary, and in only a few cases was special rehabilitation needed. The average length of stay has also been reduced, from 10.7 to 6.7 weeks. The percentage of patients rated as "symptom-free" has not, however, been increased by phenothiazines; the improvement has been confined to a shift from the "psychotic" to the "residual symptom" group, probably in part due to the striktness of our criteria for recovery.

Details are given of the change in the pattern of treatment of schizophrenia in a general hospital psychiatric unit over the past 13 years. It is suggested that a major revolution has occurred in the treatment possibilities of this illness, which can now also be carried out so easily in a general rather than a mental hospital setting. Skilled handling of the physical treatments is most important, with a determination to use every combination of treatments likely to help any individual patient.
Statistical Note.-The probabilities were calculated by chisquare to give some estimate of the differences, but as the original selection was not randomized the tests may not be fully appropriate. We wish to thank Dr. E. D. West for statistical advice on our figures.

We are grateful for a grant of money from Mr. Robert Sainsbury which has made this research possible.

\section{REFERENCES}

Ackner, B., Harris, A., and Oldham, A. J. (1957). Lancet, 1, 607. Guttmann, E., Mayer-Gross, W., and Slater, E. T. O.' (1939). F. Neurol. Neurosurg. Psychiat., $2,25$.

Hoenig, J., Leiberman, D. M., and Auerbach, I. (1956). Ibid., 19, 130. Ivanov-Smolenskii, A. (1939). Sovetsk. Psikhonevr., 15, 16.

Ivanov-Smolenskii, A. (1939). Sovetsk. Psikhonevr., 15, 16.
Meduna, L. (1935). Z. ges. Neurol. Psychiat., 152, 235.

Reduna, L. (1935). Z. ges. Neurol. Psychiat., 152, 235.

Sakel, M.'(1935). Neue Behandlungsmethode der Schizophrenie. Perles, Vienna and Leipzig.

Wing, J. K., Monck, E., Brown, G. W., and Carstairs, G. M. (1964). Brit. f. Psychiat., 110, 10.

\title{
Place of a Double-barrelled Ileostomy in Ulcerative Colitis and Crohn's Disease of the Colon: a Preliminary Report.
}

\author{
S. C. TRUELOVE,* M.D., F.R.C.P.; HAROLD ELLIS, ${ }^{*} \dagger$ D.M., M.CH., F.R.C.S. ; \\ C. U. WEBSTER,* M.B., CH.B., F.R.C.S., F.R.C.S.ED.
}

During the past five years we have been employing a doublebarrelled ileostomy in certain selected cases of ulcerative colitis and Crohn's disease of the colon. In essence, this procedure consists in dividing the ileum about 9 in. $(23 \mathrm{~cm}$.) from the ileocaecal valve, bringing the proximal cut end of ileum to the surface in the right iliac fossa to form a standard ileostomy, and bringing the distal cut end of ileum to the surface in the right hypochondrium. By this means the colon is defunctioned and it is also easy to apply topical therapy, such as corticosteroids, to the entire colon by dripping a solution into the distal ileal stoma. In addition to its allowing efficient application of topical treatment to the colon, conservative surgery can be practised on the isolated colon without the disadvantage of a faecal stream being present. The essential aim has been to see if restoration of the continuity of the gastro-intestinal tract can be performed subsequently without relapse of the disease.

Our object now is to describe the indications we have followed for employing this procedure and to present the results obtained up to the present time. Surgical technicalities are not dealt with, as they will be covered in detail in a separate article.

\section{Indications}

Our indications for double-barrelled ileostomy have been (1) severe disease failing to respond to a full medical regime; (2) chronic disease associated with local bowel complications, such as stricture, entero-enteric fistula, or perianal complications such as recto-vaginal fistula or severe fistula-in-ano ; and (3) chronic disease in childhood associated with failure of normal development.

* From the Radcliffe Infirmary, Oxford.

t Now Professor of Surgery, Westminster Hospital Medical School, London.
It will be appreciated that the orthodox treatment for all three of these categories is total colectomy with permanent ileostomy, although some would be suitable for the less orthodox procedure of subtotal colectomy with ileo-rectal anastomosis as employed by Aylett (1959).

\section{Results}

Thirty-one cases have been treated with double-barrelled ileostomy, the results being summarized in Tables I and II. We here describe some of the problems associated with our three indications for this procedure together with illustrative examples from each group.

\section{Severe Disease Failing to Respond to Medical Treatment}

Our experience has been that the great majority of attacks of ulcerative colitis can be terminated successfully by medical treatment. The medical management of a severe attack requires intensive hospital care, which must include certain basic general measures, such as control of water and electrolyte balance, blood transfusion, and maintenance of nutrition. In addition, specific therapeutic agents should be used to encourage rapid termination of the attack, and in our own hands the combined use of systemic prednisolone and topical hydrocortisone, applied by means of a rectal drip, has been the usual approach. Other agents such as anticholinergics-for example, propantheline bromide-and sulphasalazine (Salazopyrin) have occupied a secondary role. The regime which we have employed has already been described in detail (Truelove, 1962).

When medical treatment appears to be failing, colectomy is the orthodox treatment. If done as an emergency procedure this carries a high mortality rate even in the best hands, being 
approximately $30 \%$ in the series reported by Lennard-Jones and Vivian (1960) from St. Mark's Hospital and the Central Middlesex Hospital and in that reported by Goligher (1961) from Leeds. Moreover, it is known that attacks of ulcerative colitis may be very severe and yet be followed by years of freedom from symptoms. Therefore, if the acute disease can be controlled by a lesser measure which leaves open the possibility of retaining the colon, there is an obvious advantage ; especially so as radical surgery can always be employed as a final resort if the lesser measure is unsuccessful.

However, our experience with this group of cases has been disappointing. Sometimes the disease has continued unabated

Table I.-Essential Details of the Patients Treated by Double-barrelled Ileostomy (Age of Patient Refers to Time of Ileostomy)

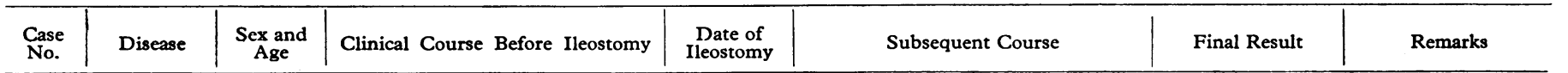

\begin{tabular}{|c|c|c|c|c|}
\hline 2 & $\begin{array}{l}\text { U.C. and } \\
\text { Christras } \\
\text { disease }\end{array}$ & $\mathbf{M}$ & 36 & $\begin{array}{l}\text { Severe first attack complicated by } \\
\text { torrential haemorrhage from the } \\
\text { bowel (presumably related to the } \\
\text { bleeding diathesis) and pyo- } \\
\text { derma gangrenosum am serme settling } \\
\text { Severe first attack never setling } \\
\text { completely in spite of intensive } \\
\text { medical treatment }\end{array}$ \\
\hline 3 & $\begin{array}{l}\text { U.C. } \\
\text { followed } \\
\text { by } \\
\text { Crohn's } \\
\text { disease }\end{array}$ & $\mathbf{M}$ & 36 & $\begin{array}{l}\text { Attacks of bloody diarrhoea for five } \\
\text { years. Last attack was severe and } \\
\text { was complicated by rectal stric- } \\
\text { ture and recto-vaginal fistula, } \\
\text { but the ileostomy was pertformed } \\
\text { because of severity of illess } \\
\text { Intermittent attacks of severe } \\
\text { bloody diarrhoea with involve- } \\
\text { ment of whole colon. Colonic } \\
\text { biopsy showed typical ulcerative } \\
\text { colitis on three occasions. Fis- } \\
\text { tula-in-ano treated by conserva- } \\
\text { tive surgery. Attacks becoming } \\
\text { more severe }\end{array}$ \\
\hline 5 & U.C. & $\mathbf{M}$ & 44 & $\begin{array}{l}\text { Eight years' intermittent bloody } \\
\text { diarrhoea, terminating in very } \\
\text { severe attack complicated by } \\
\text { massive ischio-rectal abscess }\end{array}$ \\
\hline 6 & U.C. & $\mathbf{F}$ & 48 & $\begin{array}{l}\text { Attacks of bloody diarrhoea for } 34 \\
\text { years, with chronic pyelone- } \\
\text { phritis for last two years, with } \\
\text { chronic uraemia }\end{array}$ \\
\hline 7 & U.C. & $\mathbf{M}$ & 24 & $\begin{array}{l}\text { Five years' history of ulcerative } \\
\text { colitis, culminating in severe } \\
\text { attack }\end{array}$ \\
\hline 8 & U.C. & $\mathbf{M}$ & 36 & $\begin{array}{l}\text { Two years' history of bloody diarr- } \\
\text { hoea. Admitted with severe } \\
\text { relapse not responding to medi- } \\
\text { cal treatment }\end{array}$ \\
\hline 9 & U.c. & $\mathbf{F}$ & 35 & $\begin{array}{l}\text { Attacks of severe bloody diarrhoea } \\
\text { for } 20 \text { years. Abdominal pain } \\
\text { was a prominent feature }\end{array}$ \\
\hline 10 & U.C. & $\mathbf{F}$ & 21 & $\begin{array}{l}\text { Transferred by helicopter from } \\
\text { another hospital with severe } \\
\text { first attack complicated by mas- } \\
\text { sive haemorrhage from bowel }\end{array}$ \\
\hline 11 & $\begin{array}{c}\text { Crohn's } \\
\text { disease }\end{array}$ & $\mathbf{M}$ & 13 & $\begin{array}{l}\text { Continuous bowel symptoms for } \\
9 \text { years, with severe stunting of } \\
\text { growth and inanition }\end{array}$ \\
\hline 12 & U.C. & $\mathbf{M}$ & 45 & $\begin{array}{l}\text { Emergency transfer from another } \\
\text { hospital with severe first attack. } \\
\text { After transfer, developed per- } \\
\text { foration of colon }\end{array}$ \\
\hline 13 & U.C. & $\mathbf{M}$ & 47 & $\begin{array}{l}\text { Emergency transfer from another } \\
\text { hospital with severe relapse of } \\
\text { ulcerative colitis of one year's } \\
\text { standing. Failed to respond to } \\
\text { intensive medical treatment }\end{array}$ \\
\hline 14 & U.C. & F & 6 & $\begin{array}{l}\text { Severe ulcerative colitis for } 2 \frac{1}{2} \\
\text { years, complicated by cortico- } \\
\text { steroid myopathy }\end{array}$ \\
\hline 15 & U.c. & $\mathbf{M}$ & 29 & $\begin{array}{l}\text { Severe first attack not responding } \\
\text { to medical treatment }\end{array}$ \\
\hline 16 & U.C. & $\mathbf{F}$ & 40 & Severe attacks of bloody diarrhoea \\
\hline 17 & U.c. & & 43 & $\begin{array}{l}\text { for } 24 \text { years } \\
\text { Severe attacks of bloody diarrhoea } \\
\text { for } 5 \text { years and persistent anaemia }\end{array}$ \\
\hline
\end{tabular}

Group 1. Severe Disease

\begin{tabular}{l|c|c|} 
May & $\begin{array}{c}\text { Persistent haemorrhage from isolated } \\
\text { bowel. Emergency colectomy per- }\end{array}$ & Dead
\end{tabular}

bowel. Emergency colectomy performed, but patient died from peritonitis 24 hours later

July
1959

Great improvement in general condition and able to pursue full activities, but some bowel symptoms persisting. Colectomy with ileo-

Apri rectal anastomosis January 1964 tive colectomy four months later in view of gross damage to rectum

Augus

At first well. Then developed severe abdominal pain, followed by large bleed from ileostomy. Barium follow-through showed ulcerative ileitis. Laparotomy showed typical Crohn's disease of terminal ileum, confirmed histologically. Resection of terminal ileum and closure of ileostomy, August 1961. Theremild well und January 1964. when igmed Sigmoid toning of colon. Colonic biopsy stoning of colon's Colonic biops ded to local corticosteroid treatment and dichloroprednisolone by mouth

August Abscess drained surgically. Great improvement in general condition, and returned to full work. Rectum ruined by ischio-rectal abscess; elective colectomy was therefore performed September 1961

March Marked improvement in general condition. Blood urea became normal. Weight gain $56 \mathrm{lb}$. (25 kg.). Devel 1964. Treated by colectomy and ileo-rectal anastom col

August

ileo-rectal anastomosis

apid remission after ileostomy, which was closed in February 1962. Attacks recurred from Decembe was performed in June 1963

October

At first did well, with great impr

ment in general great improvereturn to full work. Later, bowel symptoms returned. Elective colectomy performed in October 1962.

Octobe

1961.

Continued to have bowel symptoms,

including abdominal pain, and elective colectomy was performed in September 1962. Developed andiple intraperitoneal abscesses After ileostomy later

October

severe toxic state with marked pyrexia, toxic state with marked pyrexia,
semi-coma, and jactitation, and also massive haemorrhage from the bowel. Emergency colectomy performed

$\underset{1962}{\text { January }}$

Small-intes

otomy

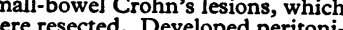
were resected.

March Died three weeks later from chronic peritonitis

June
1962

Five days after ileostomy he developed a confluent staphylococcal pneumonia which did

July

September

Developed peritonitis and died

Continued to have bowel symptoms although his general condition improved. Elective col

January

1963

May
1964

Well,

Symptoms settled. Ileostomy closed April 1964

Early result good small-bowel showed acute flare-up of

ell, with ileo-

Well, with permanent

ileostomy
Well, but on local corticosteroid treatment per rectum

Well, with permanent ileostomy

Well, with ileo- Not fit for colectomy rectal anastomosis in 1961

Well, with permanent

Well, with perileostomy

Dead

This case illustrates the difficulty of disulcerative between and Crohn's disease of colon

in 1961

Well, with

permanent

ileostomy

Dead

Dead

Dead

Well, with

permanent

Symptoms have returned 
despite the defunctioning ileostomy, and emergency colectomy has been necessary while the patient was still seriously ill-for example, Case 10. In other patients there has been temporary benefit, but the disease process has subsequently again become severe and necessitated colectomy, although this was usually an elective procedure-for example, Case 8.

\section{Chronic Disease Associated with Local Bowel Complications}

Our standard approach in such cases involves a three-stage procedure :

Stage 1.-Creation of a double-barrelled ileostomy, to be followed by local treatment to the defunctioned colon.

TABLE I.-Contd.

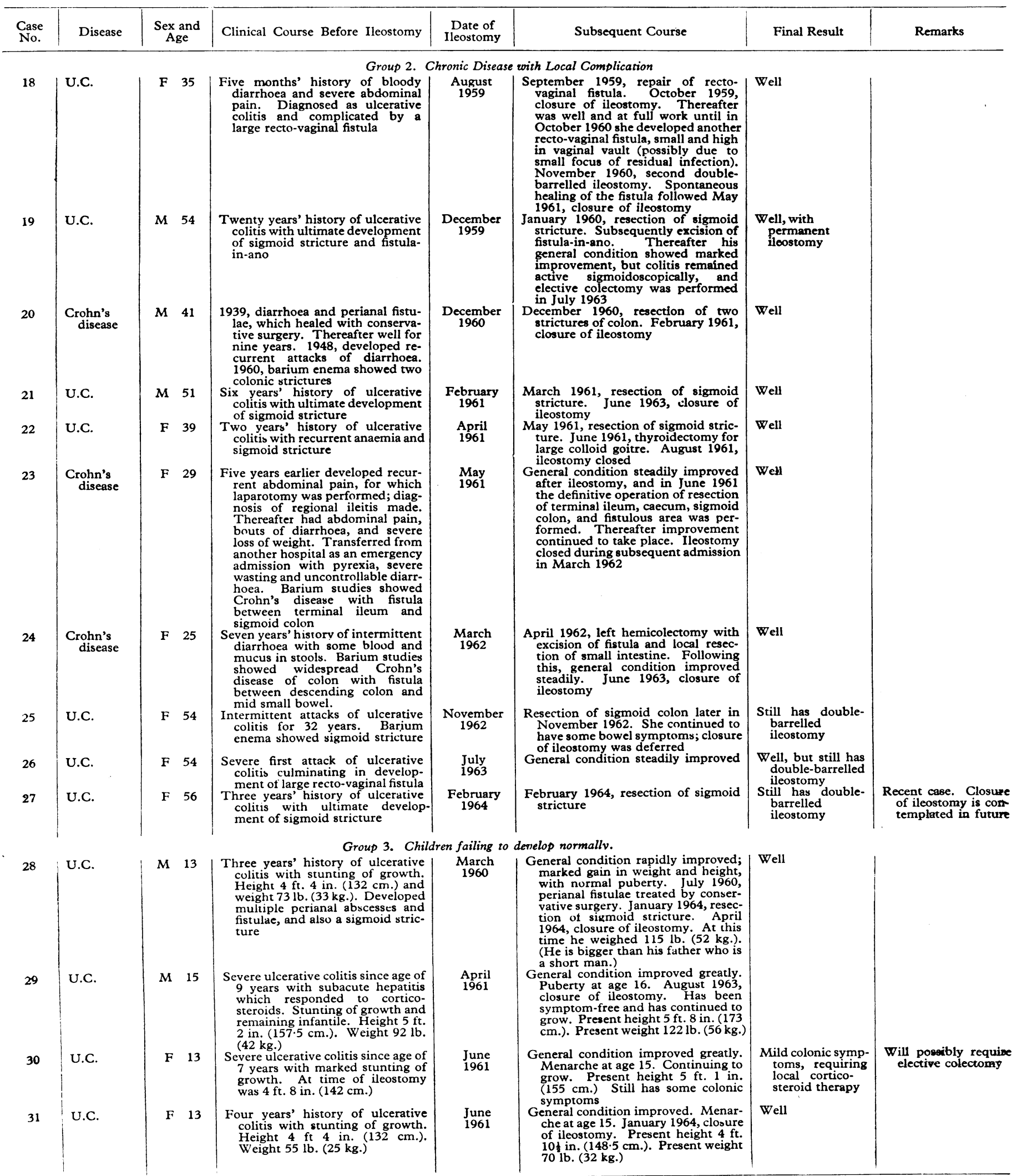


TABLE II.-Summary of Results

\begin{tabular}{lc|c|c|c|c|c}
\hline & $\begin{array}{c}\text { No. of } \\
\text { Cases }\end{array}$ & $\begin{array}{c}\text { No. With } \\
\text { Closure of } \\
\text { Ileostomy }\end{array}$ & $\begin{array}{c}\text { No. Still } \\
\text { With } \\
\text { Ileostomy }\end{array}$ & $\begin{array}{c}\text { Well } \\
\text { After } \\
\text { Colectomy }\end{array}$ & Deaths \\
\hline Group 1 & $\cdots$ & 17 & 2 & 1 & 8 & 6 \\
Group 2 & $\cdots$ & 10 & 6 & 3 & 1 & 0 \\
Group 3 & $\cdots$ & 3 & 1 & 0 & 0 \\
\hline
\end{tabular}

Stage 2.-The definitive procedure: either laparotomy with local resection of the affected portion of the bowel, to be followed by further medical treatment, or repair ef recto-vaginal fistula or fistula-in-ano.

Stage 3.-Closure of ileostomy.

Three general points are worth making about this three-stage procedure. First, it is usual for us to perform the stages with a minimum of several weeks between them and to apply vigorous medical treatment, both systemic and topical, throughout the entire period to damp down the underlying disease. Secondly, it has been found that resection of portions of a defunctional colon is technically easy. Thirdly, little attention need be paid to classical points of section, because in the absence of a faecal stream the blood supply is adequate for perfect healing no matter where the colon is divided; in other words, the most limited resection is feasible.

\section{Chronic Disease in Childhood Associated with Failure of Normal Development}

In some examples of ulcerative colitis in childhood it is possible to hold the disease in check reasonably well with corticosteroid treatment, but at the price of preventing the child from developing normally. The reason for the failure to grow and to pass through puberty is probably complex, and can be attributed in part to the disease and in part to the corticosteroid treatment.

In a few of these patients in whom we have been anxious to preserve the colon, if possible, a double-barrelled ileostomy has been done and only local corticosteroid treatment employed for the colitis. The results in the small group in which we have used this technique have been encouraging. Growth in height and weight has been rapidly resumed and puberty reached. It has been our practice to leave the colon uncoupled until the secondary sex characteristics are established and ideally until the child is as big as the parent of the same sex.

\section{Discussion}

A surgical procedure to isolate the colon was first described by Brown (1913), who performed a terminal ileostomy and caecostomy. Among his 10 cases there were several which were probably examples of ulcerative colitis. The use of topical therapy in ulcerative colitis likewise has a long history. For example, Hurst (1921) made use of an appendicostomy to allow the colon to be irrigated, although the therapeutic agents at his disposal can have had little beneficial effect. Topical therapy with corticosteroids applied per rectum has been in use in this hospital since 1955 (Truelove, 1956, 1957), and independent controlled trials have demonstrated that the treatment is beneficial (Truelove, 1958; Watkinson, 1958; Matts, 1960). It was therefore a logical step to see whether a double-barrelled ileostomy with diversion of the faecal stream would make local corticosteroid treatment more effective in severe ulcerative colitis. In addition, it also seemed possible that isolating the colon and applying local corticosteroid treatment would allow some local complications to be treated by limited surgery rather than by colectomy.

The first of these possibilities has not materialized. If severe ulcerative colitis does not respond to a full medical regime it is unlikely that the addition of a double-barrelled ileostomy with intensive local therapy will control the disease.
If the attack is acute and medical treatment is failing, an emergency colectomy should be performed even though this is still a dangerous operation. If the attack is less acute it may be best to carry out a double-barrelled ileostomy even though colectomy may be required later. In these circumstances the colectomy is usually an elective operation and comparatively easy to perform.

In our second category of patients-that is, those with certain local colonic or rectal complications-the technique of doublebarrelled ileostomy combined with local corticosteroid therapy and limited surgery to the isolated colon has been encouraging. We intend to continue with this combined technique in suitable selected cases.

In the special group of children with stunted growth due to ulcerative colitis or to its treatment with corticosteroids, the results have also been encouraging. It can be questioned whether this approach to the treatment of ulcerative colitis in childhood is justified in view of the risk of carcinoma of the colon in such cases (Lagercrantz, 1955; Michener et al., 1961). However, a variety of other factors influence the development of carcinoma in ulcerative colitis (Edwards and Truelove, 1964), especially the presence of continuous symptoms, and it is therefore possible that if the patient is rendered entirely symptomfree the risk of carcinoma may be reduced.

In this article we have grouped together ulcerative colitis and Crohn's disease affecting the colon as if they were one and the same disease, which may indeed be so. Without concerning ourselves with this philosophical question, we nevertheless believe that a double-barrelled ileostomy followed by limited surgery is especially valuable in those patients with the clinical picture of Crohn's disease affecting a part of the colon.

It may seem strange that we have called this a preliminary report when we have been using the technique for five years. However, as ulcerative colitis and Crohn's disease can recur after years of freedom from symptoms, we judge that prolonged observation of the present cases and of others will be necessary before we can assess its value with a good measure of assurance. At present we are satisfied that the technique described is a valuable addition to the treatment of ulcerative colitis and Crohn's disease of the colon in selected cases.

\section{Summary}

Thirty-one selected patients with ulcerative colitis or Crohn's disease of the colon have been treated during the past five years with double-barrelled ileostomy combined with local steroid treatment of the isolated distal bowel.

The aims have been efficient topical therapy, the possibility of conservative surgery to the isolated colon, and the feasibility of restoring the continuity of the bowel subsequently without relapse of the disease.

The cases fall into three groups: (1) those with fulminating disease ; (2) those with local bowel complications; and (3) those with chronic disease in childhood.

The results in the second and third groups have been encouraging. In the first group, however, although some patients rapidly responded to treatment, others failed to be controlled.

\section{REPERENCES}

Aylett, S. (1959). Postgrad. med. F., 35, 67.

Brown, J. Y. (1913). Surg. Gynec. Obstet., 16, 610.

Edwards, F. C., and Truelove, S. C. (1964). Gut, 5, 1.

Goligher, J. C. (1961). Brit. med. f., 1, 151.

Hurst, A. F. (1921). Guy's Hosp. Rep.; 71, 26.

Lagercrantz, R. (1955). Acta paediat. (Uppsala), 44, 302

Lennard-Jones, J. E., and Vivian, A. B. (1960). Brit. med. \%., 2, 96,

Lennard-Jones, J. E., and Vivian, A. B.

Matts, S. G. F. (1960). Lancet, 1, 517. New M., Gage, R. P., Sauer,
Newgl. f. Med., 265, 1075.

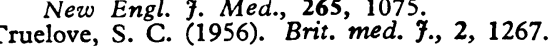

(1957). Ibid., 1, 1437.

(1958). Ibid., 2, 1072

(1962). Practitioner, 189, 269.

Watkinson, G. (1958). Brit. med. F., 2, 1077. 